\title{
Fluoride retention in the mouth during awake and sleep
}

\author{
Chenghua Pai, Yoshiaki Ono, Hidekazu Oba, Takahiro Miki, Kosuke Tanase, Tethufumi Sano, Shoji Takahashi, Koji Watanabe and \\ Shigeru Watanabe* \\ Department of Human Development \& Fostering, Division of Pediatric Dentistry, School of Dentistry, Meikai University, Japan
}

\begin{abstract}
Objectives: The purpose of this study was to evaluate the effect of salivary flow rate on fluoride retention in the mouth and to measure the site-specificity of them when six healthy adults were awake and when they had been sleeping.

Methods: $40 \mathrm{mg}$ of $\mathrm{NaF}$ and $5 \mathrm{ml}$ distilled water were mixed with $0.15 \mathrm{~g}$ of agarose which was heated until the agarose dissolved. Aliquots were pipetted into holders (diameter $4 \mathrm{~mm}$, depth $1 \mathrm{~mm}$ ) and there were bonded onto mouth guards produced from each subject. The bonding sites were on the upper anterior buccal (UAB), the upper posterial buccal (UPB), and the lower anterior lingual (LAL). When the subjects were awake, the mouth guards were fixed in the mouth and exposed to saliva for 15, 45 minutes. The agarose was taken out of the holder and put into $2 \mathrm{ml}$ of distilled water for 90 minutes and the fluoride concentration were measured by a fluoride ion meter. To examine the retention of fluoride in the mouth during sleep, the mouth guards were placed before going to bed ( $0: 00$ am.) and removed at 6:30 am and the fluoride concentration measured as above. Results: The fluoride clearance from various sites in the mouth was extremely lower when subjects were asleep than when they were awake.

When the subjects were awake, the half-times (the time for the initial fluoride concentration to decrease by half) were highest in UAB and lowest in LAL. When the subjects had slept, the clearance rates of fluoride from the gel were also showed the same results of the above.

Conclusion: The retention of fluoride in the mouth is affected by salivary flow rate and the fluoride concentration in the saliva was kept at high level for a long time during sleeping.
\end{abstract}

\section{Introduction}

Salivary clearance rates in different parts of the mouth are known to vary. Lecomte and Dawes [1] studied the rates of clearance of potassium chloride from agarose gels positioned at different sites in the mouths of subject. The clearance halftimes on the buccal surfaces of the upper anterior teeth were the longest of any site in the mouth. Weatherell, et al. [2] and Watanabe [3] reported the same results. These show that the saliva secreted into oral cavity is not perfectly mixed. Prior to these researches, Weatherell, et al. [4] reports the difference by the fluoride distribution in the mouth after fluoride rinsing. Duckworth [5] and Heath [6] have also reported oral fluoride retention after use of fluoride rinse. These researches demonstrate the mechanism of the salivary clearance reported by Dawes [7]. According to Lear [8], the salivary flow rate in the sleep is almost similar to the zero, but there are few reports the clearance of the fluoride in the sleep.

The purpose of this research was to measure the site-specificity of fluoride clearance when the subjects were awake and when they had been sleeping.

\section{Materials and methods}

The study was approved by the Ethics Committee of Meikai University.

$40 \mathrm{mg}$ of $\mathrm{NaF}$ and $5 \mathrm{ml}$ distilled water were mixed with $0.15 \mathrm{~g}$ agarose which was heated until the agarose dissolved. Aliquots were pipetted into holders (diameter $4 \mathrm{~mm}$, depth $1 \mathrm{~mm}$ ) and these were bonded onto mouth guards produced from plaster casts of each subject. The bonding sites were on the labial of maxillary incisors (UAB), the buccal of left maxillary molars (UPB) and the lingual of lower incisors (LAL). When the subjects were awake, the upper and lower mouth guards were fixed in the mouth and exposed to saliva for 15, 45 minutes. The agarose was taken out of the holder and put into $2 \mathrm{ml}$ of distilled water mixed with $0.1 \mathrm{ml}$ of the total ion strength adjustment buffer (TISAB $\square$, Thermo Orion) for 90 minutes and the fluoride concentration was measured by a fluoride ion meter (Thermo Orion). The fluoride concentration of the agarose held in the holder of each mouth guard was measured six times, and holders in which the mean concentration of agarose was more than 2 SD from the mean were excluded. To examine the retention of fluoride in the mouth during sleep, the mouth guards were placed before going to bed (0:00 am.) and removed at 6:30 am and the fluoride concentration measured as above.

The subjects, 6 adults who were all in good health and whose salivary flow rates exceed $0.3 \mathrm{ml} / \mathrm{min}$ were selected. Before the experiment, the subjects were explained the purpose and got their cooperation.

In order to, determine the effects of site specificity of salivary clearance, the data were analyzed by analysis of variance in randomized blocks and by Duncan`s New Multiple Range Test.

\section{Results}

Figure 1 shows the comparison of the mean halftimes of each place, expressed as a standard in the value at LAL. The halftimes were lowest

Correspondence to: Shigeru Watanabe, Department of Human Development \& Fostering, Division of Pediatric Dentistry, School of Dentistry, Meikai University, Japan, Tel: 81-49-279-2742, Fax: 81-49-286-1321, E-mail: Shigeru@dent.meikai.ac.jp

Key words: salivary flow rate, fluoride, salivary clearance

Received: June 01, 2017; Accepted: June 12, 2017; Published: June 14, 2017 
in LAL and were highest in UAB. There were significant differences between the LAL and UAB $(\mathrm{p}<0.01)$, and between the LAL and UPB $(\mathrm{p}<0.05)$.

Table 1 shows the comparison of the mean volume of fluoride retention at 6:30 am. when the subjects had been sleeping. The fluoride concentrations were expressed as a percentage of that of the initial agarose which did not expose to saliva in the mouth. The values in LAL were also lowest, and UAB were highest. There were significant differences between the LAL and UAB $(\mathrm{p}<0.05)$ and between the LAL and UPB $(\mathrm{p}<0.05)$.

\section{Discussion}

Most studies on fluoride clearance in the mouth have been carried out when the subjects were awake, and there is little information when they were sleeping. Ekstrand, et al. [9] and Featherstone, et al. [10] have suggested that fluoride, even at low concentrations, is necessary in the oral fluids to obtain maximum caries inhibition and have concluded that continuous or frequent elevation of the fluoride concentration in the oral fluids would be advantageous.

In this study, it was shown that the fluoride concentration in the saliva was kept at high level for a long time during sleeping. In order to, prevent dental caries at the buccal surfaces of the upper anterior teeth, it seems to be good to use a fluoride rinse before going to bed.

\section{Conclusion}

The retention of fluoride in the mouth is affected by salivary flow rate and it is advisable to rinse the mouth before going to bed to keep a high-level fluoride in the mouth for long time.

Table 1. The mean volume (\%) of fluoride retention at 6:30 am. when the subjects had been sleeping. $\left({ }^{*}<0.5\right.$ : Significantly different from the mean volume of UAB).

\begin{tabular}{|c|c|c|c|}
\hline & LAL & UPB & UAB \\
\hline & Mean (S.D.) & Mean (S.D.) & Mean (S.D.) \\
\hline Subject A & $1.2 \pm 0.3$ & $1.5 \pm 0.2$ & $3.4 \pm 2.2$ \\
\hline Subject B & $1.6 \pm 0.6$ & $2.6 \pm 1.7$ & $4.0 \pm 1.7$ \\
\hline Subject C & $0.9 \pm 0.2$ & $0.6 \pm 0.2$ & $2.6 \pm 1.8$ \\
\hline Subject D & $1.8 \pm 0.6$ & $1.8 \pm 0.7$ & $3.0 \pm 2.4$ \\
\hline Subject E & $1.7 \pm 0.8$ & $4.1 \pm 1.2$ & $3.3 \pm 2.6$ \\
\hline Subject F & $2.1 \pm 0.8$ & $2.3 \pm 1.0$ & $3.5 \pm 1.4$ \\
\hline Mean & $1.6 \pm 0.6^{*}$ & $2.2 \pm 1.2^{*}$ & $3.3 \pm 1.8$ \\
\hline
\end{tabular}

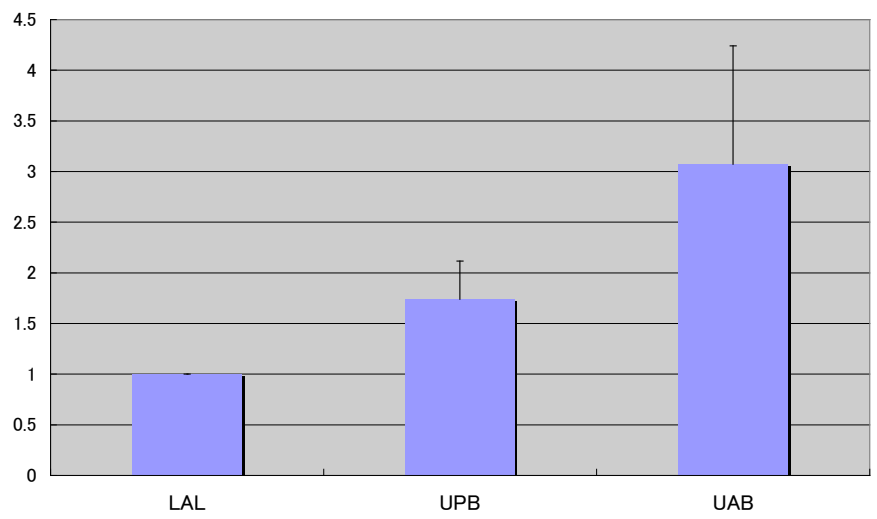

Figure 1. The comparison of the mean halftimes of each place, expressed as a standard in the value at $\mathrm{LAL}$.

$(\mathrm{P}<0.01$ : LAL vs UAB, $\mathrm{p}<0.05$ : LAL vs UPB $)$.

\section{References}

1. Lecomte P, Dawes C (1987) The influence of salivary flow rate on diffusion of potassium chloride from artificial plaque at different sites in the mouth. $J$ Dent Res 66 : 1614-1618. [Crossref]

2. Weatherell JA, Strong M, Robinson C, Nakagaki H, Ralph JP (1989) Retention of glucose in oral fluid at different sites in the mouth. Caries Res 23: 399-405. [Crossref]

3. Watanabe S (1992) Salivary clearance from different regions of the mouth in children. Caries Res 26: 423-427. [Crossref]

4. Weatherell JA, Strong M, Robinson C, Ralph JP (1986) Fluoride distribution in the mouth after fluoride rinsing. Caries Res 20: 111-119. [Crossref]

5. Duckworth RM, Morgan SN (1991) Oral fluoride retention after use of fluoride dentifrices. Caries Res 25: 123-129. [Crossref]

6. Heath K, Singh V, Logan R, McIntyre J (2001) Analysis of fluoride levels retained intraorally or ingested following routine clinical applications of topical fluoride products. Aust Dent J 46: 24-31. [Crossref]

7. Dawes C (1983) A mathematical model of salivary clearance of sugar from the oral cavity. Caries Res 17: 321-334. [Crossref]

8. Lear CS, Flanagan JB Jr, Moorrees CF (1965) The frequency of deglutition in man Arch Oral Biol 10: 83-100. [Crossref]

9. Ekstrand J, Lagerlof F, Oliveby A (1986) Some aspects of the kinetics of fluoride in saliva; in Leach SA, Edgar WM (eds): Factors relating to demineralization and remineralisation of the teeth. Oxford, IRL Press, 91-98.

10. Featherstone JDB, Oreilly MM, Shariati M, Brubler S (1986) Enhancement of remineralisation in vitro and in vivo; in Leach SA, Edgar WM (eds): Factors relating to demineralization and remineralisation of the teeth. Oxford, IRL Press, 23-34.

Copyright: (C2017 Pai C. This is an open-access article distributed under the terms of the Creative Commons Attribution License, which permits unrestricted use, distribution, and reproduction in any medium, provided the original author and source are credited. 